() Комектив авторов, 2015 г

УАК [616-056.257:577.175.532]:575

\author{
Д. Л. Бровин, Е. А. Баженова, \\ Р. Э. Попов, О. Д. Беляева, \\ А. В. Березина, Т. Л. Каронова, \\ Н. А. Корельская, Т. Г. Иванова, \\ С. Н. Пчелина, Е. И. Баранова, \\ О. А. Беркович, Е. В. Шляхто
}

\section{РАСПРЕДЕЛЕНИЕ ГЕНОТИПОВ} И ВСТРЕЧАЕМОСТЬ АЛЛЕЛЕЙ ГЕНА АЛЬДОСТЕРОН-СИНТАЗЫ У БОЛЬНЫХ АБДОМИНАЛЬНЫМ ОЖИРЕНИЕМ

Первый Санкт-Петербургский государственный медицинский университет имени академика И. П. Павлова; Северо-Западный федеральный медицинский исследовательский центр, Санкт-Петербург

\section{ВВЕДЕНИЕ}

В настоящее время абдоминальное ожирение (AO) рассматривают как один из ведущих факторов риска развития сердечно-сосудистой патологии и сахарного диабета 2-го типа [21, 22]. Установлено, что висцеральная жировая ткань, в том числе жировая ткань абдоминальной области, вырабатывает различные адипоцитокины $[5,8]$ и компоненты локальной ренин-ангиотензин-альдостероновой системы (РАAC), активность которых у пациентов с АО повышена $[1,7]$.

Изменение активности компонентов РААС не только связано с увеличением массы жировой ткани и/или присоединением артериальной гипертензии (АГ), но и генетически детерминировано $[11,12,17]$.

В настоящее время много исследований посвящено изучению полиморфизмов генов, оперирующих в РААС. ОАним из таких полиморфизмов является C-344Т-(CYP11B2)-полиморфизм гена альдостерон-синтазы $[3,11]$.

По результатам ряда исследований, носительство -344Т-аллеля гена альдостерон-синтазы ассоциировано с АГ, увеличением активности компонентов РААС $[4,14]$. Вместе с тем, по данным других авторов не выявлены ассоциации между С-344Т-полиморфизмом гена альдостерон-синтазы и увеличением активности РААС, риском развития сердечно-сосудистой патологии, тяжелой резистентной АГ $[10,18]$.

На сегодняшний день выполнено немного исследований, посвященных изучению С-344Т-полиморфизма гена альдостерон-синтазы у пациентов с АО и метаболическим синдромом, и их результаты противоречивы $[6,13,19]$.
Таким образом, целью нашей работы было оценить распределение генотипов и встречаемость аллелей гена альдостерон-синтазы у больных АО.

\section{МАТЕРИАЛ И МЕТОДЫ ИССЛЕДОВАНИЯ}

Обследованы 140 больных AO (IDF, 2005 г.) (90 женщин и 50 мужчин), жителей Санкт-Петербурга. Средний возраст больных АO составил 44,6 $\pm 0,6$ года, окружность талии (ОТ) у мужчин была $111,2 \pm 1,7$ см, у женщин $-98,8 \pm 1,4$ см. Индекс массы тела (ИМТ) рассчитывали по формуле Кетле: масса тела/рост ${ }^{2}$ (кг/м²) [2]. При этом за нор-

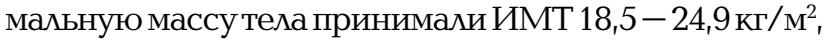
ИМТ 25,0 - 29,9 кг/м² расценивали как избыточную массу тела, а за ожирение принимали показатель ИМТ $\geq 30 \mathrm{Kг} / \mathrm{M}^{2}$.

Отягощенная по сердечно-сосудистой патологии наследственность была выявлена у 91 \% пациентов с АО. Курили 36,6 \% больных АО. Метаболический синдром (MC) (IDF, 2005) был верифицирован у 49,2 \% пациентов с АО. Среди больных АО и МС у 77,6 \% пациентов была выявлена АГ (при этом среди всех больных АО, как с метаболическим синдромом, так и без МС, АГ наблюдалась у 49,7 \% пациентов), у 67,2 \% была обнаружена гипертриглицеридемия, у 43,1 \% - нарушение толерантности к глюкозе или сахарный диабет 2-го типа, и у 62,1 \% пациентов с АО и МС отмечался сниженный уровень холестерина липопротеинов высокой плотности (ХС АПВП). Группу сравнения составили 56 обследованных (38 женщин и 18 мужчин) без АО и АГ (средний возраст $-41,0 \pm 1,1$ года).

Активность ренина плазмы (АРП) и концентрацию альдостерона плазмы крови оценивали методом радиоиммунного анализа (Immunotech, Франция). Уровень инсулина сыворотки крови определяли с помощью метода иммуноферментного анализа ( $D R G, C Ш А)$. Аипидный спектр сыворотки крови, уровень глюкозы плазмы крови оценивали на анализаторе «COBAS INTEGRA 400/700/800» (Германия). Аля оценки уровня инсулинорезистентности использовалась малая модель гомеостаза (Homeostasis Model, HOMA) с вычислением индекса инсулинорезистентности НОМА-ИР [15]. Полиморфизм С-344Т-гена альдостерон-синтазы определяли методом полимеразной цепной реакции с последующим рестрикционным анализом [9].

При статистической обработке использовали программы «SPSS 17.0RU» и программной системы «Statistika» для Windows (версия 5.5). Аанные

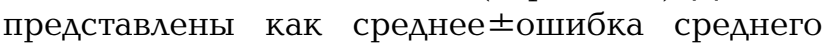
$(\mathrm{M} \pm \mathrm{m})$. Анализ частотных характеристик качественных показателей проводился с помощью непараметрического метода Фишера. Аля выявления связей между исследуемыми параметрами применялся корреляционный анализ с расчетом коэфффициента корреляции по Пирсону. Аля описания от- 
носительного риска развития заболевания рассчитывали отношение шансов (OR). Критерием статистической значимости полученных результатов считали общепринятую величину р $<0,05$.

\section{РЕЗУЛЬТАТЫ ИССЛЕДОВАНИЯ И ИХ ОБСУЖДЕНИЕ}

АРПу больных АО была выше, чем у обследован-

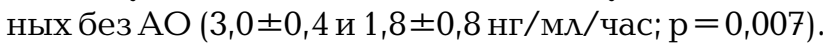
Уровень альдостерона плазмы крови $(169,1 \pm 15,0$ и $114,7 \pm 13,2$ пг/мл; $>0,05)$ и соотношение «альдостерон/ренин» $(11,6 \pm 1,2$ и $21,5 \pm 4,8 ; \mathrm{p}>0,05)$ у пациентов с АО и в группе сравнения не различались.

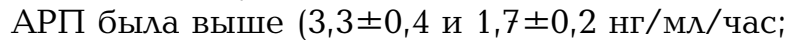
$\mathrm{p}=0,002)$, а соотношение «альдостерон/ренин» $(10,5 \pm 1,5$ и $12,8 \pm 1,8 ; \mathrm{p}>0,05)$ ниже у пациентов с АО и сопутствующей АГ, чем у больных АО без АГ. Уровень альдостерона плазмы крови в исследуемых группах пациентов не различался $(153,9 \pm 10,6$ и $166,7 \pm 13,3$ пг/мл; $\mathrm{p}>0,05)$.

Распределение C-344C-, С-344T-, Т-344Т-генотипов и встречаемость $-344 \mathrm{C}$ - и -344T-аллелей гена альдостерон-синтазы у больных АО и в общей популяции не различались (табл. 1).

У больных АО, носителей различных генотипов гена альдостерон-синтазы, ИМТ, ОТ, липидный спектр сыворотки крови, уровни глюкозы плазмы и инсулина сыворотки крови, АРП, уровень альдостерона плазмы крови и соотношение «альдостерон/ренин» не различались $(\mathrm{p}>0,05)$ (табл. 2). При этом уровень артериального давления, как систолического (САA), так и диастолического ( $\triangle \mathrm{A} A)$, был выше у носителей -344Т-аллеля гена альдостеронсинтазы, чем у носителей -344С-аллеля исследуемого гена (табл. 2). Были выявлены положительные корреляционные связи между уровнем САА и АРП $(\mathrm{r}=0,2 ; \mathrm{p}=0,003)$, а также между уровнем $\triangle \mathrm{A} \triangle$ и АРП $(\mathrm{r}=0,1 ; \mathrm{p}=0,003)$ у больных АО.

Распределение генотипов и встречаемость аллелей гена альдостерон-синтазы была оценена в группе больных АО с сопутствующей АГ и без АГ. У больных АО с сопутствующей АГ встречаемость -344T-аллеля была выше, а генотипа C-344С ниже, чем у пациентов с АО без сопутствующей артериальной гипертензии (табл. 3).

Распределение C-344C-, С-344Т- и Т-344Т-генотипов и встречаемость -344C- и -344Т-аллелей гена альдостерон-синтазы у пациентов с АО и МС и у пациентов с АО без метаболического синдрома не различалось $(\mathrm{p}>0,05)$.

Учитывая выявленную нами связь между активностью РААС и уровнями СА $\triangle$ и $\triangle A$ А, а также большую встречаемость -344Т-аллеля гена альдостеронсинтазы у больных $\mathrm{AO}$ и сопутствующей АГ, чем у пациентов с АО без АГ, был рассчитан риск развития АГ у больных АО, носителей -344Т-аллеля гена альдостерон-синтазы. Было установлено, что риск
Та блица 1

Распределение С-344C-, С-344T-, Т-344Т-генотипов и встречаемость -344С- и -344Т-аллелей гена альдостеронсинтазы у больных абдоминальным ожирением и в общей популяции

\begin{tabular}{|c|c|c|c|}
\hline \multirow[b]{2}{*}{ Генотип } & \multicolumn{2}{|r|}{ Группа } & \multirow[b]{2}{*}{$\mathrm{P}$} \\
\hline & $\begin{array}{c}\text { общая популяция } \\
(\mathrm{n}=126)\end{array}$ & $\begin{array}{c}\text { больные абдоминальным } \\
\text { ожирением }(\mathrm{n}=140)\end{array}$ & \\
\hline $\mathrm{C}-344 \mathrm{C}, \%$ & 16,7 & 10,5 & $>0,05$ \\
\hline C-344T, \% & 51,6 & 48,7 & $>0,05$ \\
\hline $\mathrm{T}-344 \mathrm{~T}, \%$ & 31,7 & 40,8 & $>0,05$ \\
\hline Алиели & & & \\
\hline$-344 \mathrm{C}$ & 0,42 & 0,35 & $>0,05$ \\
\hline$-344 \mathrm{~T}$ & 0,58 & 0,65 & $>0,05$ \\
\hline
\end{tabular}

развития АГ у этих пациентов увеличивается в 13,46 раза $(\mathrm{OR}=13,46 ; 95 \%$ CI 3,01 ? 59,04; $\mathrm{p}=0,004)$.

Одной из значимых причин АГ является генетически обусловленное увеличение активности фрермента альдостерон-синтазы, в том числе ассоциированное с C-344T-(CYP11B2)-полиморфизмом гена альдостерон-синтазы [14]. При этом носительство -344Т-аллеля и Т-344Т-генотипа данного гена связано с развитием АГ, гипертрофии левого желудочка и риском ишемического инсульта $[16,23,24]$.

В нашем исследовании распределение Т-344C-, С-344C- и Т-344Т-генотипов и встречаемость -344Tи -344С-аллелей гена альдостерон-синтазы во всех исследуемых группах не различались $(\mathrm{p}>0,05)$. ОАнако была выявлена ассоциация между наличием АГ и носительством -344Т-аллеля гена альдостеронсинтазы: у больных АО с сопутствующей АГ -344Таллель гена альдостерон-синтазы встречался чаще, чем у пациентов с АО без АГ, что подтверждается данными ряда исследований $[4,24]$.

Таблица 2

Антропометрические параметры, уровни артериального Аавления, показатели липидного и углеводного обменов, активность ренин-ангиотензин-альдостероновой системы у больных абдоминальным ожирением - носителей различных генотипов гена альдостерон-синтазы

\begin{tabular}{|c|c|c|c|}
\hline \multirow[b]{2}{*}{ Показатель } & \multicolumn{3}{|c|}{ Генотип гена альдостерон-синтазы } \\
\hline & $\begin{array}{l}\mathrm{C}-344 \mathrm{C} \\
(\mathrm{n}=15)\end{array}$ & $\begin{array}{c}\text { T-344T }+\mathrm{C}-344 \mathrm{~T} \\
(\mathrm{n}=132)\end{array}$ & $\mathrm{P}$ \\
\hline Индекс массы тела, кг/м² & $31,8 \pm 1,2$ & $32,1 \pm 0,8$ & $>0,05$ \\
\hline Окружность талии, см & $101,7 \pm 3,2$ & $102,5 \pm 2,8$ & $>0,05$ \\
\hline $\begin{array}{l}\text { Систолическое АА, } \\
\text { мм рт. ст. }\end{array}$ & $124,4 \pm 4,8$ & $133,6 \pm 2,9$ & 0,04 \\
\hline $\begin{array}{l}\text { Аиастолическое АА, } \\
\text { мм рт. ст. }\end{array}$ & $78,8 \pm 2,6$ & $84,1 \pm 1,2$ & 0,04 \\
\hline $\begin{array}{l}\text { Холестерин липопротеи- } \\
\text { нов высокой плотности, } \\
\text { ммоль/л }\end{array}$ & $1,3 \pm 0,1$ & $1,3 \pm 0,1$ & $>0,05$ \\
\hline Триглицериды, ммоль/л & $1,5 \pm 0,2$ & $1,7 \pm 0,2$ & $>0,05$ \\
\hline Глюкоза, ммоль/л & $5,3 \pm 0,3$ & $5,6 \pm 0,2$ & $>0,05$ \\
\hline Инсулин, мМЕ/мл & $6,2 \pm 1,7$ & $4,0 \pm 0,2$ & $>0,05$ \\
\hline НОМА-ИР & $25,1 \pm 5,9$ & $18,0 \pm 1,0$ & $>0,05$ \\
\hline $\begin{array}{l}\text { Активность ренина } \\
\text { плазмы, нг/мл/час }\end{array}$ & $2,6 \pm 0,9$ & $2,8 \pm 0,5$ & $>0,05$ \\
\hline $\begin{array}{l}\text { Уровень альдостерона, } \\
\text { пг/мл }\end{array}$ & $119,5 \pm 19,6$ & $148,0 \pm 15,3$ & $>0,05$ \\
\hline $\begin{array}{l}\text { Соотношение "альдосте- } \\
\text { рон/ренин" }\end{array}$ & $86,3 \pm 26,8$ & $120,4 \pm 13,8$ & $>0,05$ \\
\hline
\end{tabular}


Таблица 3

Распределение С-344C, C-344T, Т-344T-генотипов и встречаемость -344С- и -344Т-аллелей гена альдостеронсинтазы у больных абдоминальным ожирением с сопутствующей артериальной гипертензией и без артериальной гипертензии

\begin{tabular}{l|c|c|c}
\hline \multirow{2}{*}{ Генотип } & \multicolumn{2}{|c|}{ Больные абдоминальным ожирением } & \multirow{2}{*}{ Р } \\
\cline { 2 - 3 } & $\begin{array}{c}\text { артериальная } \\
\text { гипертензия (+) (n=70) }\end{array}$ & $\begin{array}{c}\text { артериальная } \\
\text { гипертензия (-) (n=70) }\end{array}$ & \\
\hline С-344С, \% & 2,9 & 15,2 & $\mathbf{0 , 0 0 8}$ \\
С-344T, \% & 51,4 & 43,5 & $>0,05$ \\
T-344T, \% & 45,7 & 40,6 & $>0,05$ \\
Аллели & & & \\
-344С & 0,34 & 0,28 & $>0,05$ \\
-344Т & 0,72 & 0,48 & $\mathbf{0 , 0 0 6}$
\end{tabular}

Вместе с тем было установлено, что у больных АО, носителей -344Т-аллеля исследуемого гена,

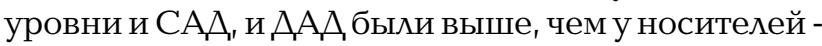
$344 \mathrm{C}$-аллеля этого гена. При проведении математического анализа было выявлено, что у больных АО, носителей -344Т-аллеля гена альдостерон-синтазы, риск развития АГ увеличивается в 13,46 раза. В некоторых работах также выявили увеличение уровней CА $\triangle$ и $\triangle A \triangle А$ у носителей $-344 \mathrm{~T}$-аллеля данного гена [4]. ОАнако большинство авторов отмечают ассоциацию между носительством -344Т-аллеля гена альдостерон-синтазы и увеличением только CAА $[23,24]$.

Таким образом, в нашем исследовании установлена непосредственная связь между носительством -344Т-аллеля гена альдостерон-синтазы и риском развития АГ у пациентов с АО, жителей СанктПетербурга.

\section{ВЫВОДЫ}

1. Распределение генотипов и встречаемость аллелей гена альдостерон-синтазы у больных абдоминальным ожирением и в общей популяции не различались.

2. У больных абдоминальным ожирением - носителей -344Т-аллеля гена альдостерон-синтазы чаще встречалась артериальная гипертензия, чем у носителей C-344C- и C-344Т-генотипов этого гена.

3. Носительство -344Т-аллеля гена альдостеронсинтазы ассоциируется с увеличением риска развития артериальной гипертензии у больных абдоминальным ожирением.

\section{ЛИТЕРАТУРА}

1. Баженова Е. А., Беляева О. А., Березина А. В. и gр. Ренин-ангиотензин-альдостероновая система у больных абдоминальным ожирением и артериальной гипертензией // Артериальная. гипертензия. - 2013. - Т. 19. - № 5. C. $389-396$.

2. Благоскионная Я. В., ШАяхто Е. В., Бабенко А. Ю. Эндокринология: учеб. для мед. вузов. - СПб.: СпецЛит, 2004. 398 c.

3. Alvarez-Madrazo S. L., Mackenzie S. M., Davies E. et al. Common polymorphisms in the CYP11B1 and CYP11B2 genes: evidence for a digenic influence on hypertension // Hypertension. - 2013. - Vol. 61 (1). - P. 232-239.

4. Barbato A., Russo P., Siani A. et al. Aldosterone synthase gene (CYP11B2) C-344T polymorphism, plasma aldosterone, renin activity and blood pressure in a multi-ethnic population // J. Hypertens. - 2004. - Vol. 22 (10). - P. 1895- 1901.

5. Batra A., Siegmund B. Role of visceral fat. // Dig. Dis. 2012. - Vol. 30. - № 1. - P. 70 - 74 .

6. Belline N. M., Foucn L., Fumeron F. et al. Association of the $-344 \mathrm{~T}>\mathrm{C}$ and the $3097 \mathrm{G}>\mathrm{A}$ polymorphisms of CYP11B2 gene with hypertension, type 2 diabetes, and metabolic syndrome in French population // Am. J. Hypert. - 2010. - Vol. 23 (6). P. $660-667$.

7. Cassis L. A., Police S. B., Yiannikouris F., Thatcher S. E. Local Adipose Tissue Renin-Angiotensin System // Curr. Hypertens. - 2008. - Vol. 10. - № 2. - P. 93-98.

8. Fuentes E., Fuentes F., Vilahur G. et al. Mechanisms of Chronic State of Inflammation as Mediators That Link Obese Adipose Tissue and Metabolic Syndrome // Mediator Inflamm. 2013. - Vol. 2013. - P. 11.

9. Gu D., Ge D., He J. et al. Haplotypic analyses of the aldosterone synthase gene CYP11B2 associated of stage-2 hypertension in northern Han Chinese // Clin. Genet. - 2004. Vol. 66 (5). - P. 409-416.

10. Hlubocka Z., Jachymova M., Heller S. et al. Association of the $-344 \mathrm{~T} / \mathrm{C}$ aldosterone synthase gene variant with essential hypertension // Physiol Res. - 2009. - Vol. 58 (6). - P. 785-792.

11. Ji L., Cai X., Zhang L. et al. Association between polymorphism in the renin-angiotensin-aldosterone system genes and essential hypertension in the Han Chinese Population // Plos. one. - 2013. - Vol. 28. - № 8 (8). - P. e72701.

12. Kim H. K., Lee H., Kwon J. T., Kim H. J. A polymorphism in AGT and AGTR1 gene is associated with lead-related high blood pressure // J. Renin Angiotensin Aldosterone Syst. - 2014. № 16. - pii: 1470320313516174. [Epub ahead of print]

13. Kim Y. R., Kim S. H., Kang S. H. et al. Association of CYP11B2 polymorphisms with metabolic syndrome patients // Biomed. Rep. - 2014. - Vol. 2 (5). - P. $749-754$.

14. Li Y., Yang P., Wu S. L. et al. Effect of CYP11B2 gene $344 \mathrm{~T} / \mathrm{C}$ polymorphism on renin-angiotensin-aldosterone system activity and blood pressure response to hydrochlorothiazide // Zhonghua Yi Xue Yi Chuan Xue Za Zhi. - 2012. Vol. 29 (1). - P. 68-71.

15. Matthews D., Hosker J., Rudeski D. et al. Homeostasis model assesment: insulin resistance and beta-cell function from fasting plasma glucose and insulin concentration in men // Diabetologia. - 1995. - Vol. 28. - № 7. - P. 412-419.

16. Munshi A., Sharma V., Kaul S. et al. Association of the $344 \mathrm{C} / \mathrm{T}$ aldosterone synthase (CYP11B2) gene variant with hypertension and stroke // J. Neurol. Sci. - 2010. - Vol. 296 $(1-2)$. - P. $34-38$.

17. Pacholczyk M., Ferenc T., Kowalski J. et al. Association of angiotensin-converting enzyme and angiotensin II type I receptor gene polymorphisms with extreme obesity in Polish individuals // DNA Cell. Biol. - 2013. - Vol. 32 (8). - P. 435-444.

18. PayneJ.R., DhamraitS.S., Toor I.S. etal. The-344T $>$ C promoter variant of the gene for aldosterone synthase (CYP11B2) is not associated with cardiovascular risk in a prospective study of UK healthy men // Atherosclerosis. - 2004. - Vol. 174 (1). - P.81 - 86.

19. Russo P., Lauria F., Loguercio M. et al. -344C/T Variant in the promoter of the aldosterone synthase gene (CYP11B2) is associated with metabolic syndrome in men // Am. J. Hypert. 2007. - Vol. 20 (2). - P. 218-222.

20. Saidi S., Mahjoub T., Almawi W. Y. Aldosterone synthase gene (CYP11B2) promoter polymorphism as a risk factor for ischaemic stroke in Tunisian Arabs // J. Renin Angiotensin Aldosterone Syst. - 2010. - Vol. 11 (3). - P. 180-186. 
21. Scharma A. M. The Obese Patient with Diabetes Mellitus: from Research Targets to Treatment Options // Am. J. Med. 2006. - Vol. 119. - № 5 (Suppl. 1). - P. S17-S23.

22. Shields M., Tremblay V.S., Janssen I. Abdominal Obesity and Cardiovascular disease Risk Factors within Body Mass Index Categories // Health Reports. - 2012. - Vol. 23. - № 2. P. $7-15$.

23. Sookoian S., Gianotti T. F., Gonzales C. D. et al. Association of the C-344T aldosterone synthase gene variant with essential hypertension: a meta-analysis // J. Hypert. - 2007. - Vol. 25 (1). - P. 5-13.

24. Tiago A. D., Badenhorst D., Nkeh B. et al. Impact of reninangiotensin-aldosterone system gene variants on the severity of hypertension in patients with newly diagnosed hypertension // Am. J. Hypertens. - 2003. - Vol. 16 (12). - P. 1006- 1010.

\section{РЕЗЮМЕ}

Д. Л. Бровин, Е. А. Баженова, Р. Э. Попов, О. Д. Беллева, А. В. Березина, Т. Л. Каронова, Н. А. Корельскал, Т. Г. Иванова, С. Н. Пчелина, Е. И. Баранова, О. А. Беркович, Е. В. Шляхто

Распределение генотипов и встречаемость аллелей гена альдостерон-синтазы у больных абдоминальным ожирением

Обследованы 140 больных абдоминальным ожирением

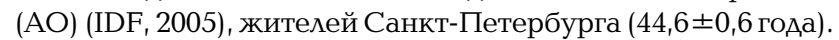
У 49,2 \% пациентов с АО был выявлен метаболический синAром (MC) (IDF, 2005). Самым частым компонентом МС у больных АО была артериальная гипертензия (АГ). Распределение генотипов и встречаемость аллелей гена альдостерон-синтазы у больных АО и в группе сравнения (56 обследованных без АО, 41,0 1,1 года) не различалось ( $>$ >0,05). Уровни артериального давления (АА), как систолического, так и диастолического, были выше у носителей -344Т-аллеля гена альдостерон-синтазы. Активность ренина плазмы крови, уровень альдостерона плазмы крови, антропомет- рические параметры, показатели липидного спектра сыворотки крови и углеводного обмена у пациентов с АO, носителей различных генотипов гена альдостерон-синтазы, не различались. Носительство -344Т-аллеля гена альдостеронсинтазы у больных АО ассоциировано с увеличением риска развития артериальной гипертензии.

Ключевые слова: абдоминальное ожирение, артериальная гипертензия, ренин-ангиотензин-альдостероновая система, полиморфизм, альдостерон-синтаза.

\section{SUMMARY}

D. L. Brovin, E. A. Bazhenova, R. E. Popov, O. D. Belyaeva, A. V. Berezina, T. L. Karonova, N. A. Korelskaya, T. G. Ivanova, S. N. Pchelina, E. I. Baranova, O. A. Berkovich, E. V. Schlyakhto

Distribution of genotypes and alleles of the aldosteronesynthase gene in patients with abdominal obesity

We observed 140 patients with abdominal obesity (AO) (IDF, 2005), the residents of St. Petersburg (44.6 \pm 0.6 years). Metabolic syndrome (MS) (IDF, 2005) was diagnosed in $49.2 \%$ of patients with $\mathrm{AO}$. The most frequent component of MS in patients with $\mathrm{AO}$ was arterial hypertension $(\mathrm{AH})$. The distribution of genotypes and -alleles of the aldosterone-synthase gene in patients with $\mathrm{AO}$ and in the comparison group (56 subjects without $\mathrm{AO}, 41.0 \pm 1.1$ years) didn't differ ( $p>0.05$ ). Levels of both systolic and diastolic blood pressure (BP) were higher in carriers of $-344 \mathrm{~T}$ allele of aldosterone-synthase gene. Plasma renin activity, plasma aldosterone and glucose levels, anthropometric parameters, serum blood lipids and carbohydrate metabolism indices in obese patients with different genotypes of aldosterone-synthase gene didn't differ. $-344 \mathrm{~T}$ allele of aldosterone-synthase gene in patients with $\mathrm{AO}$ is associated with the increased risk of $\mathrm{AH}$.

Keywords: Abdominal obesity, arterial hypertension, reninangiotensin-aldosterone system, polymorphism, aldosteronesynthase.
(․ А. В. Васендин, С. В. Мичурина, И. Ю. Ищенко, 2015 г. УАК [612.438:612.57]-092.4

\author{
Д. В. Васендин, С. В. Мичурина, \\ И. Ю. Ищенко
}

\section{СТРУКТУРНЫЕ ИЗМЕНЕНИЯ} В ТИМУСЕ В АНАБОЛИЧЕСКОЙ ФАЗЕ ПОСЛЕ ВОЗДЕЙСТВНЯ ЭКСПЕРИМЕНТАЛЬНОЙ ГИПЕРТЕРМИИ

Сибирский государственный университет геосистем и технологий, г. Новосибирск; Новосибирский научно-исследовательский институт клинической и экспериментальной лимфологии СО РАМН

\section{ВВЕДЕНИЕ}

Тимус, являясь центральным органом лимфоидной (иммунной) системы и эндокринной железой одновременно, представляет собой, по-существу, связующее звено между этими двумя органными системами, ответственными за осуществление процессов адаптации к различным факторам окружающей среды, в том числе и к такому, как высокая внешняя температура. Всестороннее изучение структурных основ и регуляторных механизмов регенерации биологических тканей обеспечивает теоретическое обоснование для разработки новых технологий стимуляции репаративных процессов, что увеличивает возможность направленного на восстановление органов и тканей воздействия.

Целью исследования было выявить и оценить особенности структурных изменений в тимусе крыс Вистар в восстановительном периоде после проведения экспериментальной гипертермии (ЭГ).

\section{МАТЕРИАЛ И МЕТОДЫ ИССЛЕДОВАНИЯ}

В эксперименте использовались крысы-самцы Вистар, по 15 животных в каждую временную точку. Разогревание экспериментальных животных 